\title{
Paul Raskin, Journey to Earthland: The Great Transition to Planetary Civilization,
}

Boston: Tellus Institute, 2016, ISBN: 978-0-9978376-0-5,

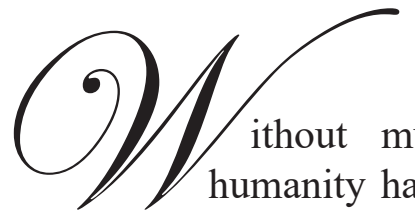

much planning or foresight, has embarked on a momentous and potentially dangerous journey, as we have become the first species in the 4-billlion-year history of planet earth to dominate change on planet earth. As Paul Raskin writes: "We are bound together on a precarious passage to a land unknown and unnamed." [1] Do we really understand what we are doing or why, and do we have any real idea where we are headed? Many possible destinations are not good. The voyage could lead to barbaric wars, to ecological, social and moral degradation, and even, perhaps, to extinction. And if our voyage ends badly so will the voyages of many other species. That's why it's desperately important that we have a clearer sense of where we would like to end up. We need a sketch map of our journey, and that is what Paul Raskin offers us in Journey to Earthland. His map shows the paths we need to avoid, but also points us towards destinations that look good both for us and our descendants, both human and non-human. Indeed, its third section offers a wonderful sketch of a flourishing future world that we hope is somewhere not too far ahead of us. As Raskin insists, hope itself is an important virtue on such a dangerous journey.

Big historians will welcome Raskin's argument that we are unlikely to find the guidance we need if we persist in "looking through narrow apertures ... [in a] world, awash in specialized reports." What we will need, instead, is a world whose educational institutions help us link specialized knowledge within "big systems, big ideas, and big history, thereby connecting cosmology and social history to the understanding of the contemporary condition and underscoring the problem of the future." [99] This is why Journey to Earthland begins with a brief telling of the big history story. After all, knowing where you are is one key to good navigation. [99] Paul Raskin's own career has by David Christian, Macquarie University

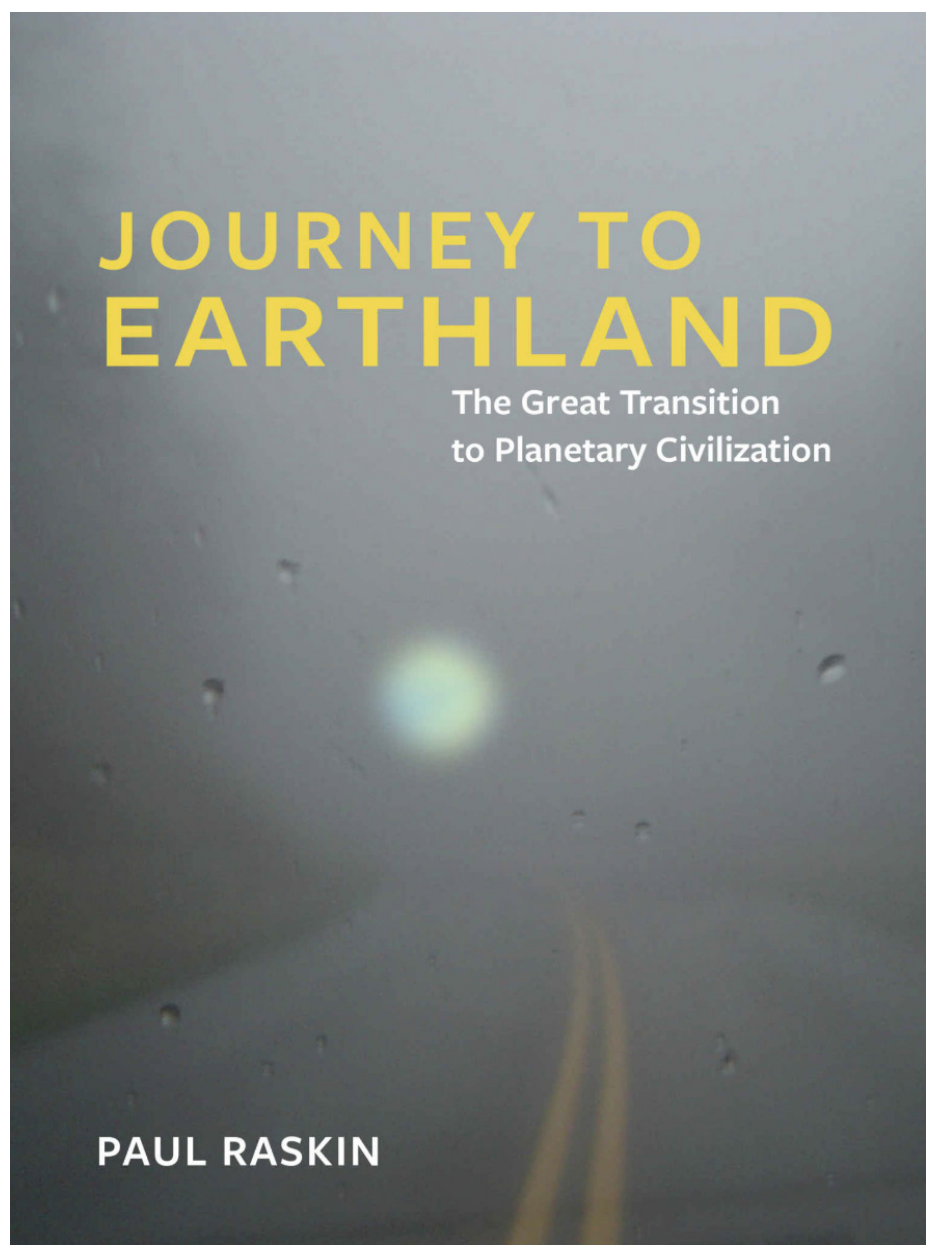

long been dedicated to broad, holistic thinking. Trained as a physicist and a philosopher, he eventually left the academy in the 1970s, appalled by the Cold War's flirtation with catastrophe. In 1976, he founded the Tellus Institute to conduct trans-disciplinary research on the complex, dangerous and unpredictable journey to which humanity is now committed.

Journey to Earthland summarizes the results of a lifetime's thinking about the human journey and its destination. "Earthland" itself represents the linked and inter-dependent trans-national community of 
humans that is emerging today, though still hard to see clearly. Raskin insists that the global level of integration is new and of vast significance, because it is this ramshackle global community, with its outdated "zombie ideologies" of consumerism, chauvinism and never-ending growth [21] and its inner inequalities, tensions and conflicts, that will take the crucial navigational decisions in the near future. "The world-as-a-whole becomes a primary arena for the contending forms of consciousness that will determine whether the Planetary Phase will be an era of social evolution or devolution, environmental restoration or degradation." [19]

"Departure", the first part of Raskin's book, explores today's world and the forces that will shape the near future. The major forces for change-corporations, governments, armies, ideologies, and the networks that flourish in their interstices - have all arisen within a fragmented world. None seem capable of navigating or speaking for Earthland as a whole. [31] Can we hope for the rise of new transformative forces that can speak for humanity as a whole, perhaps a "Global Citizens' Movement" of some kind, formed from spontaneous movements for change, and the many transnational organizations that already work towards a more just and egalitarian world? [32,33]

"Pathway", the second part of the book, describes a world in which the technological possibilities seem vast, but the political technologies are missing. That world has many possible futures that Paul Raskin groups within three main pathways: Barbarization, Conventional Worlds, and Great Transitions. The bleakest pathways lead to a barbaric, totalitarian world of rich fortress zones that use military and technological power to keep at bay impoverished global majorities; even bleaker scenarios follow that world towards breakdown and catastrophe. Conventional World scenarios are messier, shaped by a chaotic muddling through, dominated by market forces that can never really solve the fundamental problem of increasing consumption in a world of limited resources. The most optimistic scenarios envisage a "Great Transition" that begins with growing pressure towards fundamental change, driven, perhaps, by emerging "Global Citizens' Movements" and governmental initiatives that strengthen already apparent trends. The slowing of population growth in most affluent countries, if extended to most of the world, could stabilize and eventually cut population growth. And the waste present in modern capitalist economies means there is plenty of fat that could be cut from modern economies, perhaps from military or advertising budgets or from the most egregious forms of consumerism. And many of the technologies we will need are already here or in the making. Raskin argues that there are many trends, visible today, which, if maintained, could lead towards a sustainable future. To support those trends, though, we will need greater clarity about the future and a growing sense of global citizenship, the global equivalent of the sense of national citizenship that shaped most peoples' identities in today's world. In an increasingly inter-dependent world, will it be that much harder to imagine a global community than it was to imagine the multi-million communities of modern nation states?

In my view, Part 3 of Journey to Earthland, is the most successful and powerful part of the book. It is called "Destination", and it imagines a complex journey that arrives at a good destination. It is written as an imaginary history of the hundred years from 1984 to 2084. Significant change begins with the formation of a Global Citizens Movement in 2021, whose power grows during a period of global crisis in the mid 2020s. For some 20 years, the global citizens' movement collaborates with governments that work hesitantly towards greater sustainability. But in the 2040s the alliance breaks down, conservative forces rally, and there is a period of conflict out of which there arises a new Commonwealth of Earthland in 2048. Once established this pushes for more radical reforms. By the late 2050s, "The revolutionary turn 
toward planetary civilization was in full swing." [75]

Though far from perfect, the world that begins to be constructed at this point is rich in promise. Values shift profoundly, stressing the quality of life over consumption and economic growth, stressing the importance of equality and sufficiency, an ethos of "enough for all", and "enough is enough". The idea of global citizenship begins to seem as normal as that of national citizenship had seemed in the late twentieth century. And, like traditional nationalisms, the idea of global citizenship turns out to be compatible with vast regional and cultural diversity, and distinct patterns of social and economic organization. Some regions are organized, like most twentieth century societies, around markets, though with regulations that steer market activity towards sustainable and socially productive goals. Other regions are more collectivist in their attitudes to economics, and some consist largely of small, self-sufficient communities. But in all communities, the idea of ecocentrism, the idea that we must live with the biosphere rather than in opposition to it, begins to seem obvious and natural, and with the global support of GAIA, the "Global Assembly for Integrated Action", much of the ecological damage of the past is slowly undone. A drastic reduction in wasteful expenditure, including military expenditure and advertising, means that global levels of material welfare rise above those of the late twentieth century, and material wealth is spread much more equally: "in a typical region, the highest earning 10 percent have incomes three to five times greater than the poorest 10 percent." [103] Global populations stabilize at about 8 billion, Universal health care and education and guaranteed levels of material security begin to seem normal, and most people work less hard than in the past. They are "time affluent". And they live in a world in which optimism about the future has largely replaced the dystopian fears of the late twentieth century.

A utopian vision? Perhaps. But we have no good reasons for ruling out such futures, and we already have many of the technological and intellectual resources needed to build a better world. Besides, as Raskin argues so persuasively, imagining a better world as vividly as we can is itself a vital step towards building a better future for our descendants. "The vision of an organic planetary civilization lies before us as possibility and exigency. We may never reach that distant shore, but what matters most is imagining its contours and traveling in its direction." [113] 
